19 - Tempo

\title{
Ciência, saúde e desenvolvimento: a doença de Chagas no Brasil $(1943-1962)^{*}$
}

\author{
SimoneP etraglia Kropf**
}

Analisa o processo histórico de construção da doença de C hagas, descoberta em 1909, como entidade médica específica e problema de saúde pública no B rasil, focal izando a atuação de um posto de pesquisa do Instituto O swaldo C ruz, criado em 1943, no interior de $\mathrm{M}$ inas $\mathrm{G}$ erais. Sugere que o trabalho realizado neste posto proporcionou um consenso básico para que a doença alcançasse legitimidade científica e social, e que os significad os atribuídos à doença neste processo estiveram diretamente referidos aos debates sobre as relações entre ciência, saúde e desenvolvimento, no contexto da Segunda Guerra M undial.

Palavras-chave: doença de C hagas - Ciência - Saúde Pública

Science, health and development: C hagas disease in Brasil (1943-1962)

$\mathrm{T}$ he article analyzes the historical process by which Chagas disease, discovered in 1909, has been constructed as a specific medical entity and a public health issue in B razil. F ocusing on the role played by an $\mathrm{O}$ swal do $\mathrm{Cruz}$ I nstitute research post created in rural M inas Gerais in 1943, it proposes that the work carried out at this post was responsible for reaching a basic consensus that al lowed the disease to attain scientific and social legitimacy. T he meanings assigned to $C$ hagas disease during this process

\footnotetext{
${ }^{*}$ Artigo recebido em fevereiro de 2005 e aprovado para publicação em abril de 2005.

** Pesquisadora da C asa de O swal do C ruz/F iocruz. D outoranda em $\mathrm{H}$ istória da U niversidade Federal F luminense.E mail: simonek@coc.fiocruz.br.

$\overline{T e m p o, ~ R i o ~ d e ~ J a n e i r o, ~ n o ~ 19, ~ p p . ~ 107-124 ~}$
} 
were directly related to debates about the connections between science, health and development within the context of the World War II.

Keywords: Chagas disease- science- public health

L a science, la santéet le développement: la maladiedeC hagas au Brésil (19431962)

L e texte analyse le processus historique de construction de la maladie de Chagas, découverte en 1909, en tant qu'entité médicale spécifique et problème de la santé publique au Brésil, en étudiantl'action d'un poste de recherche de l'I nstituto O swaldo C ruz créé en 1943 àl'intérieur de M inas G erais. O n suggère que les recherches menées par cette équipe là ont établi des assises pour que cette mal adie ait obtenue légitimité scientifique et sociale, et que ce processuss'est reporté aux signifiés atribués, dans le contexte de la II Guerre mondiale, aux liens entre la science, la santé et du développement.

M ots-clefs: maladie de Chagas- science- santé publique

Introdução

O mal de Chagas, ou tripanossomíase americana, é uma doença endêmica causada pelo parasito Trypanosoma cruzi e transmitida por um inseto conhecido no Brasil como barbeiro. 0 risco de contraí-la está associado às precárias habitações nas áreas rurais, pois este inseto se aloja nas frestas das paredes de barro das casas da população pobre. D escoberta em 1909, na cidade mineira de $\mathrm{L}$ assance, por $\mathrm{C}$ arlos $\mathrm{C}$ hagas, médico e pesquisador do Instituto Oswaldo C ruz (IOC, também conhecido como Instituto de $M$ anguinhos), a doença tornou-se objeto de uma larga tradição de pesquisa, no B rasil e no exterior, e foi considerada importante problema de saúde pública no continente sul-americano.

Visando discutir a dimensão histórico-social das relações entre ciência, saúde pública e projetos de desenvolvimento no Brasil, nas décadas de 1940 e 1950, pretendo analisar o processo histórico pelo qual a caracterização da doença de Chagas como entidade médica específica e problema sanitário de importância continental foi construída e alcançou legitimidade científica e social, institucional izando-se como campo de pesquisa e objeto de políticas públicas de saúde. Focalizarei a atuação dos pesquisadores do Centro de E studos e Profilaxia da M oléstia de Chagas (CE PM C), posto do 
Ciência, saúde edesenvolvimento: a doença de Chagas no B rasil (1943-1962)

IOC em Bambuí, M inas Gerais, entre sua criação, em 1943, até o falecimento, em 1962, de seu diretor, E mmanuel D ias, discípulo de Carlos Chagas que assumiu a liderança nas pesquisas sobre a doença feitas no instituto naquelas décadas.

Segundo Charles Rosenberg, as doenças não constituem realidades dadas na natureza a serem "desvendadas" pelos médicos e cientistas, mas são histórica e socialmente construídas, no que diz respeito tanto aos significados sociais a elas atribuídos, quanto às categorias e aos conteúdos pelos quais o conhecimento médico-científico as define como fenômenos biológicos particulares. É mediante este processo social de enquadramento (framing) que elas assumem o estatuto de entidades conceitualmente específicas e reais ${ }^{1}$. E sta é uma perspectiva que se aproxima de abordagens contemporâneas da história e da sociologia da ciência, que, seguindo a trilha aberta por T homas K uhn em 1962, consideram o conhecimento científico como fruto de uma prática col etiva que se desenvolve num dado momento histórico, um sistema de crenças e convenções, cujo processo de produção e certificação pressupõe acordos e negociações entre grupos situados em diversas esferas da vida social².

A pesar de sua descoberta ter sido enaltecida, no Brasil e no exterior, como grande feito da ciência nacional, e da importância que conferiu à nova enfermidade como uma das grandes endemias rurais do país, $C$ arlos $C$ hagas faleceu, em 1934, num momento em que a doença estava cercada de incertezas, relativas à sua caracterização clínica e à sua dimensão epidemiológica. M eu argumento é o de que o CE PM C proporcionou um consenso decisivo para que a doença fosse reconhecida como categoria específica nos sentidos biológico e social. Os cientistas associados a este posto produziram conhecimentos que a tornaram aceita como entidade clínica, expressa essencialmente por uma cardiopatia peculiar. Ao mesmo tempo, mediante intensa mobilização para divulgá-la e conquistar os interesses de outros gru-

\footnotetext{
${ }^{1}$ C harles R osenberg, "F raming disease: illness, society and history", Charles R osenberg, J anet Golden (E ds.), F raming disease. Studies in cultural history, $\mathrm{N}$ ew B runswick/N ew J ersey, R utgers U niversity Press, 1992, pp. xiii-xxvi; idem, "T he tyranny of diagnosis: specific entities and individual experience", The M ilbank Quaterly, vol. 80, n² 2, 2002, pp. 237-260.

${ }^{2}$ T homas Kuhn, A estrutura das revoluções científicas, São Paulo, Perspectiva, 3a ed., 1989. Ver Steven Shapin, " $\mathrm{H}$ istory of science and its sociological reconstructions" , $\mathrm{H}$ istory of Science, vol. $20, n^{\circ} 49,1982$, pp. 157-211.
} 
pos sociais, principalmente os médicos, eles propagaram a idéia de que, por atingir o coração, a moléstia comprometia a produtividade do trabal ho rural e, conseqüentemente, o desenvolvimento econômico das regiões afetadas, devendo ser uma prioridade para as políticas sanitárias. N este processo de produção de consenso, que envolveu dimensões cognitivas e sociais, as estratégias e os significados acionados pelos cientistas estiveram diretamente relacionados ao ambiente histórico-social, mais especificamente aos debates sobre a relação entre ciência, saúde e desenvolvimento.

A redefinição deM anguinhos após 1930: reconstruindo a tradição deCarlos Chagas sob os ventos da II Guerra M undial

A identificação da nova doença parasitária veio a somar-se a um conjunto de descobertas científicas empreendidas no cenário internacional, desde o final do século XIX, no âmbito da progressiva legitmação e institucional ização da medicina tropical inglesa ${ }^{3}$. A descoberta de Chagas tornou-se assim o grande símbolo e vitrine do projeto de Oswaldo Cruz de transformar o IOC, conforme o modelo do I nstituto Pasteur, num centro de pesquisa, ensino e produção no campo da microbiologia, especializado no estudo das chamadas doenças tropicais. R eforçand o a protozoologia como principal área de investigação do instituto, a tripanossomíase americana foi estudada, sob a liderança de Chagas, em seus vários aspectos, relativos ao transmissor, ao parasito e às características clínicas. M ais do que um objeto científico, a doença constituía o emblema de um modelo de ciência que se legitimava publicamente pela perspectiva de atender às demandas e aos interesses concretos da sociedade, identificando e solucionando problemas sanitários, tidos como ameaças a interesses econômicos e políticos, tanto na esfera pública quanto privada4. J untamente com a malária e a ancilostomose, a tripanossomíase americana foi apontada pelos cientistas e intelectuais do movimento sanitarista dos anos 10 como grande obstáculo ao progresso nacio-

\footnotetext{
${ }^{3} \mathrm{D}$ avid Arnold (E d.), Warm climates and western medicine the emergence of tropical medicine. Amsterdan/Atlanta, Rodopi, 1996.

${ }^{4}$ Jaime B enchimol (Org.), M anguinhos do sonho à vida. A ciência na belleépoque, R io de J aneiro, Casa de Oswaldo Cruz/F iocruz, 1990; N ancy Stepan, B eginnings of brazilian science: Oswaldo Cruz, medical research and policy, 1890-1920. N ew York, Science H istory Publications, 1976.
} 
Ciência, saúde edesenvolvimento: a doença de Chagas no B rasil (1943-1962)

nal, a ser superado mediante o compromisso do E stado em promover o saneamento rural do país $s^{5}$.

Contudo, começaram a surgir, entre alguns médicos, dúvidas sobre a descrição clínica da doença proposta por Chagas e, conseqüentemente, sobre sua importância epidemiológica e social. Contestava-se, sobretudo, a tese de que uma de suas manifestações principais era o bócio, distúrbio da tireóide popularmente conhecido como "papo". o argumento dos críticos era o de que, fora de $M$ inas, em muitas regiões infestadas por barbeiros, não se identificavam casos de bócio ${ }^{6}$. I niciados em 1916, num congresso médico na Argentina, e amplificados em polêmica que envolveu o próprio Chagas na Academia N acional de M edicina, em 1922/1923, tais questionamentos fizeram com que se difundisse a idéia de que a doença não passava de um problema restrito aos "rincões de $M$ inas".

M esmo que as críticas a Chagas, então diretor do IOC e do D epartamento N acional de Saúde Pública, tivessem sido motivadas por rivalidades políticas, como ressaltam alguns autores ${ }^{7}$, elas expressam sobretudo a falta de consenso para tornar aquele objeto uma realidade estável, em seus contornos tanto científicos quanto sociais ${ }^{8}$. Além da escassez de casos tidos como comprovados, os especial istas apontavam as incertezas quanto à especificidade clínica da doença e aos procedimentos de diagnóstico ${ }^{9}$. Sob tais condições, o tema encontrava-se restrito ao interesse de poucos grupos de pesquisa, no Brasil e, sobretudo, no exterior.

\footnotetext{
${ }^{5} \mathrm{G}$ ilberto H ochman, A era do saneamento. As bases da política de Saúde Pública no B rasil, São Paulo, H ucitec/AN POCS, 1998; N ísia T rindade L ima, U m sertão chamado B rasil: I ntelectuais e representação geográfica da identidade nacional, R io de J aneiro, R evan/IU PE RJ , 1999.

${ }^{6} \mathrm{~N}$ o final dos anos 30 , comprovou-se que o bócio era, de fato, uma doença totalmente distinta do mal de Chagas.

${ }^{7} \mathrm{~J}$ aime Benchimol, L uiz Antonio T eixeira, Cobras, lagartos \& outr os bichos: uma história comparada dos institutos 0 swaldo Cruz eB utantan. Rio de J aneiro, E ditora UF RJ , 1993; M arilia C outinho, "N inety years of C hagas D isease: a sucess story at the periphery". Social S tudies of Science, v. 29, n 4, 1999, pp. 519-549.

${ }^{8}$ Simone K ropf; N ara Azevedo, L uiz O távio F erreira, "Biomedical research and public health in B razil: the case of Chagas' disease (1909-1950)", Social H istory of M edicine, vol. 16, n 1, april 2003, pp. 111-129.

${ }^{9}$ Warrington Yorke, "Chagas' disease. A critical review" ,Tropical Diseases B ulletin, vol. 34, n4, march 1937, pp. 275-300. Yorke contabilizava que, além dos 29 casos agudos estudados por C hagas em $L$ assance, e de quatro casos em São Paulo, havia, fora do B rasil, 113 casos da doença "ef etivamente comprovados", conforme o critério da demonstração da presença do parasito.
} 
U m primeiro passo importante para reverter este quadro foi dado na Argentina, quando o médico C ecilio R omaña descreveu, em 1935, um sinal clínico que permitiaa fácil e imediataidentificação de casos agudos (um edema inflamatório nas pálpebras, causado pela contaminação da conjuntiva pelas fezes infectadas do barbeiro) ${ }^{10}$. A divulgação do "sinal de R omaña" entre os médicos do interior levaria ao diagnóstico de centenas de casos, em poucos anos, naA rgentina e em ou tros países, conferindo grande estímulo aos que, no $B$ rasil, pretendiam dar continuidade às pesquisas de $C$ arlos $C$ hagas.

$E$ ntre estes, estava seu filho mais velho, $E$ vandro $C$ hagas, que desenvolvia estud os sobre a forma cardíaca da doença e, em 1937, fundou, no I OC, o Serviço de $E$ studo das G randes E ndemias (SE GE ) ${ }^{11}$. I nspirado nos ideais sanitaristas do pai e financiado, em grande parte, pelo empresário e mecenas Guilherme Guinle, o projeto era criar, em cooperação com os governos estaduais, institutos para estudar as principais doenças do interior do país, como a malária, a esquistossomose, a leishmaniose e a tripanossomíase americana, com vistas a propiciar aos serviços sanitários meios concretos para sua profilaxia. E stabelecendo com pesquisadores mineiros um plano de estudo da doença de Chagas em 1939, o SE GE passou a mapear a incidência dos transmissores e a procurar novos casos da doença no estado, utilizando como principal estratégia para isto a divulgação do sinal de R omaña entre os médicos locais. E m 1940, identificou-se um importante foco da doença na pequena cidade de Bambuí, oeste de $\mathrm{M}$ inas, e os cientistas passaram a estudálo com particular atenção.

Se o SE GE significou uma iniciativa decisiva para renovar os interesses e os estudos sobre a tripanossomíase americana, não resultou, contudo, de uma diretriz institucional do IOC, de cuja estrutura administrativa e financeira o serviço possuía, na prática, grande autonomia, graças aos recur-

\footnotetext{
${ }^{10}$ Romaña fazia parte da M isión de E studios de Patología R egional Argentina, grupo criado nos anos 20 por Salvador M azza para estudar as principais doenças do interior do país, entre elas a doença de Chagas. Para o epistemólogo $\mathrm{F}$ rançois D elaporte, R omaña foi o "verdadeiro" responsável pela construção clínica da tripanossomíase americana, em função dos "erros" de C hagas, sobretudo ao correlacionar a doença com o bócio. Para uma crítica desta interpretação, que incorre no anacronismo ao recorrer a noções de erro/verdade tão questionadas pelos historiadores e pel os sociól ogos da ciência, ver S. K ropf, N . Azevedo e L . O. F erreira, "Biomedical research and public health in Brazil...", op. cit. F rançois D elaporte, La maladiedeChagas. Paris, É ditions Payot \& Rivages, 1999.

${ }^{11}$ O SE GE resultou da ampliação dos trabal hos iniciados no âmbito da Comissão de E studos da L eishmaniose Visceral, criada por E vandro Chagas em M anguinhos, em 1936.
} 
sos extra-orçamentários obtidos por $E$ vandro $C$ hagas e às relações pessoais que este mantinha com o M inistro da E ducação e Saúde. $O$ fato de $E$ vandro Chagas pretender reproduzir o projeto de ciência de seu pai fora de $M$ anguinhos ${ }^{12}$ estava relacionado à ind efinição em que a instituição se encontrava naquele momento, em função das transformações pelas quais passava a sociedade brasileira, especialmente a partir de 1930.

Com o fim da R epública Velha, o E stado assumiu o protagonismo na recomposição das forças políticas e econômicas do país, com vistas à implantação de uma nova ordem urbano-industrial. N o campo da saúde pública, este processo significou 0 aprofundamento de uma tendência que já se vinha delineando nos anos 20 , de central ização e ampliação do poder do E stado ${ }^{13}$. A reforma implementada em 1937 por Gustavo C apanema, no M inistério da E ducação e Saúde (M ES), criado em 1930, ao garantir as condições para a nova política sanitária do governo Vargas, teve grande impacto sobre $\mathrm{M}$ anguinhos, sobretudo por questionar o papel social que o instituto havia assumido, nas primeiras décadas do século $X X$, como responsável pela formulação e pela implementação da política de saúde pública no país ${ }^{14}$. N a medida em que tais atribuições passaram ao M E S, o IOC teria que redefinir seus vínculos com o campo da saúde pública ${ }^{15}$.

U m fator essencial para esta redefinição foi a II Guerra M undial, quando as doenças infecto-contagiosas assumiram grande importância como ameaças não apenas às ações militares, mas também aos interesses econômicos e políticos que as nações em disputa tinham em relação aos países

\footnotetext{
${ }^{12}$ E $\mathrm{m}$ 1940, pouco antes de falecer, vítima de desastre aéreo, E vandro Chagas propôs formalmente que o SE GE se desligasse do IOC e se transformasse num instituto vinculado diretamente ao M inistério da E ducação e Saúde.

${ }^{13}$ Gilberto H ochman, "A saúde pública em tempos de Capanema: continuidades e inovações" , H elenaBomeny (O rg.), Constelação Capanema: intelectuais epolíticas, Rio de J aneiro, E ditora F GV, 2001, pp. 127-51.

${ }^{14} \mathrm{~T}$ anto $\mathrm{O}$ swaldo $\mathrm{Cruz}$ quanto $\mathrm{Carlos} \mathrm{C}$ hagas foram ao mesmo tempo diretores do $\mathrm{IO} \mathrm{C}$ e das agências federais de saúde pública.

${ }^{15} \mathrm{D}$ urante a reforma $\mathrm{C}$ apanema, foi proposta a criação de um instituto destinado a pesquisas sobre os problemas sanitários do país, enquanto o IOC passaria a ser uma instituição essencialmente de pesquisa científica. E mbora não tenha sido implementada, a proposta revela a falta de consenso sobre qual deveria ser a identidade social do IOC em face da nova organização da saúde pública. N o que concerne a este argumento sobre as tran sformações vividas pelo IOC a partir da Revolução de 1930, o presente texto se beneficiou de pesquisa desenvolvida entre 2000 e 2002 na Casa de 0 swal do C ruz juntamente com L uiz O távio F erreira, N ara Azevedo e Wanda $\mathrm{H}$ amilton.
} 
fornecedores de matérias-primas estratégicas, entre eles o Brasil ${ }^{16}$. 0 mundo assistia a uma intensa corrida em busca de novos recursos profiláticos e terapêuticos contra estas ameaças. Os principais símbolos deste processo foram os antibióticos, especial mente a penicilina, e o D D T, usado para proteger as tropas aliadas contra os vetores do tifo e da malária, no M editerrâneo e no Pacífico. Tais avanços técnicos, ao disseminarem um grande otimismo quanto às possibilidades de vencer a luta contra as doenças, contribuíam para consolidar uma abordagem da relação entre saúde e desenvolvimento segundo a qual as intervenções sanitárias, sobretudo o combate sistemático aos vetores, eram o pré-requisito para o desenvolvimento econômico e social dos países ${ }^{17}$.

$\mathrm{N}$ o Brasil, esta tendência orientou uma nova reforma na estrutura federal da saúde pública, com a criação, em 1941, de Serviços N acionais específicos para implementar campanhas verticalizadas contra as principais doenças epidêmicas e endêmicas do país. E ntre elas, não constava a doença de Chagas, o que evidencia que este não era ainda considerado um problema relevante para a saúde pública.

Tal cenário impôs novos rumos ao IOC, primeiramente por provocar um aumento substantivo nas demandas por produtos biológicos fabricados pela instituição. $\mathrm{Com}$ a adesão do Brasil às $\mathrm{F}$ orças Aliadas, $\mathrm{M}$ anguinhos passou a servir ao esforço de guerra, fornecendo soros, vacinas e quimioterápicos. A expansão dos serviços públicos de saúde, especialmente com a criação dos Serviços $\mathrm{N}$ acionais, também trouxe novas solicitações, em termos de produtos e serviços. O IOC encontrava, assim, uma nova forma de afirmar sua identidade pública enquanto instituição a serviço da nação. F oi nesta conjuntura que H enrique Aragão assumiu a direção de M anguinhos (19421949), com o projeto de reconstruir seus tradicionais vínculos com a saúde pública, não apenas em termos do atendimento a demandas pontuais, mas com um sentido bem mais amplo, como uma nova forma de associar a ciência feita na casa de $\mathrm{O}$ swaldo $\mathrm{Cruz}$ aos interesses de um projeto nacional. $\mathrm{O}$

\footnotetext{
${ }^{16}$ André L uiz Vieira de Campos, "International H ealth Policies in Brazil: T he Serviço E special de Saúde Pública, 1942-1960" , Tese de D outorado, U niversidade do Texas, Austin, 1997.

${ }^{17}$ R andall Packard \& Peter Brown, "R ethinking health, development and malaria: historicizing a cultural model in International H ealth", M edical Anthropology, vol. 17, n 3, 1997, pp. 181-94; J ohn F arley, To cast out the disease A history of the International $\mathrm{H}$ ealth Division of the R ockefeller F oundation (1913-1951), N ew York, Oxford U niversity Press, 2004.
} 
investimento no estudo das endemias rurais, especialmente na busca de novos métodos e instrumentos de profilaxia, foi a via preferencial para esta perspectiva. Assim, assumindo os princípios do SE GE como prioridade institucional, Aragão fundou, em várias regiões do país, postos destinados a pesquisar e combater doenças endêmicas, como a bouba, a esquistossomose, o bócio endêmico e a doença de $\mathrm{Chagas}^{18}$.

Se a intenção era aproveitar a conjuntura favorável para atualizar um projeto de ciência filiado aos ideais sanitaristas de Oswal do Cruz e Carlos C hagas $^{19}$, isto só foi possível mediante os novos significados que os elementos conformadores daquele projeto assumiram no contexto particular dos anos 40. Ainda que o projeto de modernização instaurado em 1930 privilegiasse 0 mundo urbano-industrial , o tema do interior e do desenvolvimento rural ganhava um novo sentido, como condição para garantir o abastecimento de um mercado interno consumidor, capaz de sustentar o novo modelo econômi$\mathrm{Co}^{20}$. E m termos políticos e ideológicos, a centralidade, conferida pelo novo E stado ao tema do trabalho como val or primordial para a construção de uma nova nação, vinha respaldar projetos que visassem garantir melhores condições para a existência de trabalhadores sãos, fortes e produtivos, nas cidades e no campo ${ }^{21}$. E m M inas G erais, por sua vez, a preocupação das elites com a estagnação econômica do estado tornava-as sensíveis a programas destinados a aumentar a produtividade no campo, estancando o êxodo rural

\footnotetext{
${ }^{18}$ E stas eram enfermidades que não foram contempladas com a criação dos Serviços N acionais em 1941. Aragão buscava investir em áreas que não haviam sido objeto de preocupações sistemáticas por parte do E stado.

${ }^{19} \mathrm{~L}$ uiz Antonio de Castro-Santos afirma que o processo de nation-building, iniciado em 1930, terial evado a um "esvaziamento definitivo da ideologia de redenção dos sertões" e inviabilizado a continuidade do movimento sanitarista. $N$ uma perspectiva diferente, considero que as novas estruturas administravas da saúde pública brasileira significaram justamente a criação de condições institucionais e políticas concretas para a viabilização daquele projeto, que, ao mesmo tempo, se beneficiava das novas condições, técnicas e simbólicas, legadas pela experiência da guerra à afirmação da saúde como fator de desenvolvimento. L uiz Antonio de Castro-Santos, “ O pensamento sanitarista na Primeira R epública: uma ideol ogia de construção da nacionalidade", idem, 0 pensamento social no B rasil, Campinas, E dicamp, 2003, pp. 208-49, p. 249. 20 Tamás Szmrecsányi, "O desenvolvimento da produção agropecuária (1930-1970)”, in B oris F austo (org.) O B rasil Republicano: E conomia e cultura (1930-1964), Rio de J aneiro, Bertrand Brasil, $3^{a}$ ed., 1995, pp. 109-207 (H istória Geral da Civilização B rasileira, T omo III, Volume 4). ${ }^{21}$ Ângela Castro Gomes, A invenção do trabalhismo, R io de Janeiro/São Paulo, I U PE RJ N értice, 1988.
} 
e recuperando a tradicional vocação agrícola do estado, como "grande celeiro" do mercado interno nacional ${ }^{22}$.

F oi sob tais circunstâncias que, em novembro de 1943, se criou 0 CE PM C. E las forneceram não apenas as condições políticas, sociais e institucionais para este empreendimento, mas os elementos discursivos que 0 legitimavam em seu objetivo de estudar, demonstrar sua importância e combater uma doença à qual se atribuíam graves prejuízos ao trabalhador rural. E stas condições também influenciariam o projeto do CE PM C no que se refere à sua agenda de pesquisa e às estratégias para tornar tais conhecimentos aceitos e legitimados publicamente.

I dentificando o inimigo, as armas eos aliados: o estudo da doença em B ambuí

U m dos principais objetivos do CE PM C era estabelecer meios técnicos para a profilaxia da doença de Chagas. Seguindo a concepção vigente no cenário internacional, a principal estratégia era o ataque sistemático a seus vetores. D epois de um detal hado mapeamento do foco de Bambuí, D ias deu início a experiências com vários inseticidas, com vistas a testar seu poder de letalidade contra os barbeiros e, principalmente, seu poder residual, ou seja, a capacidade de manter a ação inseticida por um tempo suficiente para evitar a reinfestação do domicílio ${ }^{23}$.

E $m$ 1944, quando o D DT vinha fazendo grande sucesso no combate ao tifo e à malária no sul da I tália, D ias passou a testá-lo, com grandes expectativas, compartilhando-as com o diretor do IOC, que acompanhava de perto os trabalhos, num indício da importância que o projeto assumia entre as atividades de $M$ anguinhos. C ontudo, em 1945, ele concluiu que o produto não era eficaz contra os vetores da doença de Chagas, e os testes prosseguiram²4. E m 1948, com a colaboração do médico mineiro J osé Pellegrino, o

${ }^{22}$ Otavio Soares D ulci, Política er ecupera ção econômica em M inas G erais, B elo H orizonte, E ditora UFM G, 1999.

${ }^{23} \mathrm{E}$ mmanuel $\mathrm{D}$ ias, U m ensaio de profilaxia de moléstia de Chagas, Rio de Janeiro, I mprensa N acional, 1945.

${ }^{24} \mathrm{~A}$ realização de mel horias habitacionais foi outro método de profilaxia testado pelo C E PM C. $D$ ias realizou ensaios buscando técnicas simples de reboco das paredes que impedissem sua infestação pelos barbeiros, e chegou a implementar, em nível experimental, a construção de "casas higiênicas" que servissem de modelo para a população rural da região. E . D ias, U m ensaio deprofilaxia..., op. cit. 
CEPM C chegou a um inseticida que, mediante ensaios em laboratório, se mostrou suficientemente adequado para ser usado numa campanha de profilaxia. Quase quarenta anos após a descoberta, os cientistas tinham um instrumento concreto para uma ofensiva contra a tripanossomíase americana: o gamexane ou hexaclorociclohexano $(\mathrm{BHC})^{25}$.

U ma campanha contra uma doença pressupõe, contudo, o acordo sobre o que se pretende combater. Outro objetivo do CE PM C era estudar clinicamente a doença, especialmente em sua fase crônica, para a qual evolui a maioria dos casos e sobre a qual pairavam as principais dúvidas quanto aos enunciados de $\mathrm{C}$ hagas. $\mathrm{N}$ esta fase, como o parasito desaparece da circulação, é impossível o diagnóstico pela observação direta do sangue, e os outros métodos, na época, requeriam procedimentos especializados e nem sempre davam resultados precisos. E rafundamental estabelecer critérios para que o diagnóstico clínico orientasse a realização de provas laboratoriais.

A opção foi investir no estudo da forma cardíaca, que, do quadro clínico traçado por Chagas, era a mais aceita e atraía maior número de investigadores, ainda que se apontasse a necessidade de vários esclarecimentos ${ }^{26}$. A questão central era: como estabelecer, entre as alterações cardíacas observadas nos suspeitos de infecção chagásica, as que poderiam ser atribuídas especificamente à ação do T. cruzi e, como tal, servissem como critérios de diagnóstico seguros? $\mathrm{N}$ os termos de R osenberg, como identificar, nos traçados alterados do eletrocardiograma, sinais de uma entidade clínica particular? E ra necessário estabelecer um padrão, em termos das características destas alterações, sua freqüência e sua relação com outros fatores clínicos, que definisse um quadro típi co de cardiopatia chagásica, individualizada diante de outras cardiopatias.

E stas perguntas já haviam motivado o próprio C arlos Chagas e outros pesquisadores, como E urico Villela (seu principal colaborador neste tema), $E$ vandro Chagas e 0 argentino Salvador $M$ azza. Contudo, um fator foi fundamental para que os cientistas do CE PM C viessem a contribuir decisivamente para respondê-las: a experiência clínica de um cardiologista que, por ter observado milhares de portadores de cardiopatias na cidade do Rio de

\footnotetext{
${ }^{25} \mathrm{E}$ mmanuel D ias \& José Pellegrino, "Alguns ensaios com o gammexane no combate aos transmissores da doença de Chagas", B rasil-M édico, vol. 62, n 18-20, 1948, pp. 185-191.

${ }^{26}$ Ver Warrington Yorke, op. cit.
} 
J aneiro (entre os quais a probabilidade de haver chagásicos era pequena), era particularmente sensível a perceber características e padrões atípicos em relação ao universo com que estava familiarizado. $F$ rancisco $L$ aranja, médico do I nstituto de A posentadoria e Pensões dos Industriários, foi convidado por D ias a juntar-se ao CE PM C e, aplicando as modernas técnicas de eletrocardiografia nos casos clínicos de Bambuí, passou a estudar sistematicamente suas manifestações cardíacas. E sta foi uma característica essencial do projeto do CE PM C, que o diferenciava da agenda de pesquisa de Carlos Chagas, referida essencialmente ao domínio da parasitologia: para tornar a doença um assunto de interesse médico, os esforços de investigação foram direcionados para a pesquisa clínica, recrutando-se especialistas neste campo. A decisão de adotar este novo enquadramento, nos termos de R osenberg, foi determinante para o desenho que a doença iria assumir como entidade médica específica e para as perspectivas de torná-la reconhecida enquanto tal.

Além de definir o que deveria ser considerado o quadro el etrocardiográfico típico da cardiopatia chagásica crônica, os cientistas adotaram outras estratégias para fortalecer seus argumentos quanto à realidade clínica desta entidade, sobretudo face aos que exigiam a demonstração do parasito como critério diagnóstico indispensável. Por um lado, realizaram inquéritos em populações não previamente selecionadas, os quais, por meio de exames eletrocardiográficos, indicaram uma proporção significativa da forma cardíaca entre os casos crônicos confirmados sorologicamente. Por outro lado, reproduziram experimentalmente, em cães inoculados com o T. cruzi, uma cardiopatia crônica cujas características eletrocardiográficas, radiológicas e clínicas eram as mesmas encontradas nos seres humanos. Assim, em 1948, os cientistas concluíram:

A experiência adquirida nestes últimos anos em Bambuí, onde temos acompanhado numerosos casos, trouxe-nos a convicção de que a esquizotripanose crônica encontra expressão clínica essencialmente em uma cardiopatia bem definida em seus caracteres anátomo-patológicos, clínicos, radiológicos e eletrocardiográficos, permitindo-Ihes individualização segura ${ }^{27}$.

Segundo L aranja, o sucesso obtido na definição da cardiopatia chagásica crônica deveu-se, especial mente, ao recurso a técnicas de eletrocardio-

${ }^{27} \mathrm{~F}$ rancisco L aranja, E mmanuel D ias \& Genard N óbrega, "Clínica e terapêutica da doença de Chagas", M emórias do I nstituto Oswaldo Cruz, vol. 46, nº 2, 1948, pp. 473-529, pp. 476-77. 
grafia bem mais avançadas do que as disponíveis no tempo de Carlos Chagas, e à possibilidade de acompanhar os pacientes durante vários anos, repetindo sistematicamente os exames para conferir a recorrência dos sintomas $^{28}$. Sob a perspectiva da história da ciência à qual o presente texto está filiado, argumento que o aperfeiçoamento na capacidade técnica em detectar alterações eletrocardiográficas, embora importante, não foi o fator decisivo: era preciso que os cientistas interpretassem estas alterações como expressão de uma dada realidade específica que pretendiam demonstrar e, acima de tudo, convencessem os outros, especialistas e não especialistas, a aceitar esta interpretação ${ }^{29}$.

U ma característica fundamental que explica o sentido do trabal ho do CEPM C foi o fato de que não se limitou a produzir novos conhecimentos científicos sobre a doença, mas, ultrapassando as fronteiras do laboratório, assumiu uma dimensão política de mobilização, com vistas não apenas a divulgar o tema, mas, sobretudo, a atrair sobre ele os interesses de outros grupos sociais. A profundando uma estratégia já utilizada pelo SE GE , o principal alvo eram os médicos, especial mente os do interior, fundamentais para a identificação de novos casos da doença. Com este objetivo, D ias publicou artigos nas principais revistas médicas em que, além de apresentar informações essenciais sobre a doença, convocava tais profissionais a atuarem como aliados dos cientistas ${ }^{30}$. A associação de interesses ${ }^{31}$ assumia os seguintes termos: à medida que enviassem informações sobre casos suspeitos ou outras pistas da doença, os clínicos eram estimulados a publicar tais dados, por intermédio do IOC, nos periódicos especializados, e mesmo a iniciar pesquisas mais sistemáticas sobre 0 assunto. As respostas a esta convocação não tardaram e a doença tornou-se, sobretudo nos anos 50, um forte ele-

\footnotetext{
${ }^{28} \mathrm{~F}$. L aranja, "E volução dos conhecimentos sobre a cardiopatia da doença de C hagas. Revisão crítica da literatura", M emórias do I nstituto Oswaldo Cruz, vol. 47, nos 3-4, 1949, pp. 605-69.

${ }^{29} \mathrm{P}$ ara um estudo que ressalta o processo de negociação em torno dos dados pretensamente objetivos destes aparel hos que "revelam" as doenças, ver Christopher L awrence, "'D efinite and material': coronary thrombosis and cardiologists in the 1920s", Charles R osenberg \& J anet Golden ( $E$ ds.), F raming disease Studies in cultural history. $\mathrm{N}$ ew B runswick/N ew J ersey, R utgers U niversity Press, 1992, pp. 50-82.

${ }^{30} \mathrm{E}$ mmanuel $\mathrm{D}$ ias, "Apêlo aos clínicos do interior para a colaboração no estudo da doença de Chagas", 0 H ospital, vol. XXI, n 6, 1942, pp.921-26.

${ }^{31}$ Bruno L atour, Ciência em ação, São Paulo, U nesp, 2000.
} 
mento de identidade profissional dos "clínicos do Brasil Central", como se autodenominavam os médicos do interior.

$\mathrm{N}$ os textos que publicou ao longo dos anos 40, voltados não apenas para os médicos, mas para o público mais amplo - que incluía diversos segmentos sociais, especialmente nas áreas rurais, como educadoras, políticos, autoridades sanitárias - D ias afirmava que a doença era um grave problema para o desenvolvimento do país, na medida em que, por ser um mal cardíaco, prejudicava a capacidade produtiva dos trabalhadores rurais. Tal caracterização, bem como a ênfase retórica que se Ihe conferia, era reforçada à medida que as pesquisas sobre a cardiopatia chagásica iam avançando. $\mathrm{N}$ um momento histórico em que o val or do trabal ho assumia centralidade no imaginário político-cultural, esta foi uma estratégia discursiva de grande impacto. Por um Iado, a disseminação da idéia de que as sensações de perturbação cardíaca deveriam ser vistas pela população e pelos médicos rurais como possíveis sinais da doença potencializava as próprias condições de pesquisa sobre a questão, trazendo novos casos suspeitos a serem examinados. Por outro lado, tal estratégia imprimia aos resultados das pesquisas um significado social concreto, associado a uma dimensão central da vida das pessoas, o que, conseqüentemente, reforçava seu poder de persuasão. Assim, a propaganda de que a doença de C hagas era social mente importante, por ser uma doença do coração, foi um elemento fundamental para a produção e a certificação dos conhecimentos que definiram a cardiopatia chagásica crônica, não como estratégia posterior a este processo cognitivo, mas como uma dimensão indissociável deste.

R espaldado nos novos conhecimentos produzidos pelo CE PM C - em relação ao quadro clínico e aos critérios de diagnóstico para identificar sua dimensão epidemiológica e aos instrumentos de profilaxia - e na maior casuística da doença até então reunida no país (cerca de 600 casos em 1948), D ias passou a reivindicar, especialmente a partir de 1949, providências imediatas dos poderes públicos para combatê-la, contando para isto com o apoio decisivo dos médicos do interior. E $m$ maio de 1950, o M E S inaugurou a primeira campanha de profilaxia da doença de Chagas no B rasil, na cidade de U beraba, Triângulo $\mathrm{M}$ ineiro, região que sintetizava as expectativas em torno da recuperação econômica do $E$ stado, diretriz principal do então governo M ilton Campos. Sob a orientação do CE PM C, a aplicação de inseticidas, prevista para municípios do oeste de M inas e do norte de São Paulo, caberia 
Ciência, saúdee desenvolvimento: a doença de Chagas no B rasil (1943-1962)

ao Serviço N acional de M alária (M E S), em cooperação com a Secretaria de Saúde do E stado de M inas Gerais.

Dos rincões deM inas para o $\mathrm{B}$ rasil eo continente

A campanha de profilaxia, que na década de 1950 se estenderia a outros estados brasileiros, trouxe grande projeção à doença de C hagas nos fóruns médicos, científicos e de saúde pública, no B rasil e no exterior, conferindo progressiva visibilidade e legitimidade científica aos conhecimentos produzidos em Bambuí e atraindo o interesse de novos grupos de pesquisa. $\mathrm{No}$ Congresso B rasileiro de $\mathrm{H}$ igiene de 1951, por exemplo, foi o tema que reuniu maior quantidade de trabalhos. Ao mesmo tempo, este campo de pesquisa passava a institucionalizar-se nas universidades, especialmente nas faculdades de medicina criadas em regiões onde a doença era endêmica, como R ibeirão Preto, Triângulo M ineiro e G oiânia. Outro sinal importante de institucional ização foi a realização do Primeiro Congresso Internacional sobre D oença de Chagas, no Rio de Janeiro, em 1959.

$\mathrm{N}$ a década de 1950, $\mathrm{D}$ ias se empenharia na mobilização política para estender 0 alcance da campanha iniciada em U beraba e, principalmente, para que a Oficina Sanitária Panamericana (OSP) coordenasse um plano de combate à doença no continente. A pesar de enfrentar resistências à sua tese de que, à semelhança do que então se propagandeava para a malária, era possível erradicar os vetores da doença de Chagas $^{32}$, ele promoveu intensa articulação com cientistas e governos de diversos países sul-americanos. E m 1960, a OSP organizou, em Washington, uma reunião de peritos para discutir as perspectivas da profilaxia.

A atuação de D ias, nos anos 50, com vistas a expandir o interesse científico sobre a doença ${ }^{33}$ e institucionalizá-la como objeto das políticas sani-

${ }^{32} D$ ias defendia a erradicação dos barbeiros desde o início dos trabal hos do posto, mas, a partir de 1956, quando realizou um ensaio piloto em Bambuí, passou a afirmar que se tratava não mais de uma perspectiva remota, mas factível. As críticas a esta tese eram baseadas tanto em aspectos técnicos, quanto em orientações políticas, por parte dos que afirmavam que o combate à doença deveria privilegiar a melhoria das condições de habitação da população rural, uma vez que as intervenções sanitárias só faziam sentido se associadas a projetos mais gerais de desenvolvimento econômico e social.

${ }^{33} \mathrm{O}$ trabalho sobre a cardiopatia chagásica produzido pelos cientistas do CE PM C seria reconhecido internacional mente com a publicação numa prestigiosa revista médica norte-americana. Ver F. L aranja, E . D ias, G. N óbrega, A. M iranda, “C hagas' disease: A clinical, epidemiologic and pathologic study', Circulation, vol. 14, 1956, pp. 1035-60. 
tárias nacionais e internacionais, esteve diretamente referida ao cenário do pós-guerra. 0 tema da vinculação entre saúde e desenvolvimento ganhava nova força e sentidos num mundo em reconstrução que vivia o sonho do de senvolvimento, o qual, como aponta Arturo E scobar, constituía não apenas um conjunto de ações políticas e econômicas concretas, mas, sobretudo, um "regime de representações" a partir do qual o mundo foi ressignificado ${ }^{34}$. F oi neste campo discursivo que se propagou a crença de que os principais instrumentos para o progresso material e a superação da pobreza em todo 0 mundo eram a ciência, a técnica e o planejamento econômico, sob a coordenação de especial istas no âmbito de organizações estatais ou internacionais. N o campo da saúde, reforçava-se a confiança nos novos instrumentos tecnológicos para a tão sonhada vitória contra as doenças tropicais, que assumia importância não apenas econômica, como fator para o aumento da produtividade no chamado Terceiro M undo, mas política, como meio de impedir a disseminação da ideologia comunista nesta região. A criação da O rganização M undial de Saúde, em 1948, trouxe novas condições institucionais, políticas e simbólicas para os projetos que visavam romper o que então se definiu como "círculo vicioso da doença e da pobreza" ${ }^{35}$, dos quais se destacou o programa lançado pela OM S em 1955 para a erradicação gl obal da malária.

N o contexto brasileiro, por sua vez, a democratização, iniciada em 1945, recompunha, sob o valor da legalidade, a imagem do E stado como agente primordial de planificação do desenvolvimento, num momento em que se intensificavam os processos que vinham configurando o novo modelo econômico, voltado para a industrial ização e a urbanização. N o plano ideológico, o retorno ao regime constitucional e ao jogo partidário e o contexto da Guerra F ria projetaram ainda mais na cena pública os debates em torno das concepções e dos rumos do desenvolvimento. 0 país vivia, sob vários aspectos, a progressiva conformação daquilo que, no segundo governo Vargas e, sobretudo, durante os anos JK, constituía o model o nacional-desenvolvimentista ${ }^{36}$. A saúde, especialmente o tema do combate às endemias rurais, ga-

\footnotetext{
${ }^{34}$ Arturo E scobar, E ncountering development. The making and unmaking of the Third World, Princeton, N ew Jersey, Princeton U niversity Press, 1995, p. 6.

${ }^{35} \mathrm{C}$.-E. A. Winsl ow, Lo quecuesta la enfer midad y lo quevalela salud, Washington, Organización M undial delaSalud/O ficinaSanitaria Panamericana, mayo 1955 (PublicacionesCientíficas, $n^{\circ} 16$ ).

${ }^{36}$ Ver M aria Celina S. D 'Araújo (O rg.), As instituições brasileeras da E ra Vargas, R io de Janeiro, E dU ERJ/E d.F GV, 1999; ÂngelaC astro G omes (O rg.), 0 B rasil dej K, R io deJ aneiro, E d.F GV, 2002.
} 
Ciência, saúdee desenvolvimento: a doença de Chagas no B rasil (1943-1962)

nhava nova visibilidade no projeto político desenvolvimentista, não apenas pela expansão na capacidade administrativa do E stado ${ }^{37}$ e pelos novos recursos tecnológicos então disponíveis para as campanhas, mas também pelo significado político e simbólico que viria a assumir, num período em que as metas do desenvolvimento foram sintetizadas na grande operação de interiorização da capital do país.

\section{Conclusão}

E m 1962, um desastre automobilístico pôs fim à trajetória de E mmanuel $D$ ias. 0 processo de institucionalização da doença, no campo científico e no campo da saúde pública, continuaria avançando. Com a renovação que a biologia molecular e a engenharia genética produziram nas ciências biológicas, nos anos 60 e 70, o tema passou a despertar novos interesses de estudo, especialmente no campo da pesquisa básica. E m 1975, 0 M inistério da Saúde deu início ao primeiro inquérito nacional para mapear a incidência da doença, e logo depois o controle da transmissão vetorial foi ampliado para todo o país ${ }^{38}$.

A literatura memorialística, escrita sobretudo por médicos, enaltece a contribuição do posto de Bambuí, sob a liderança de D ias, como marco na história da doença de $C$ hagas no Brasil, apontando que seu maior mérito foi ter produzido as provas para confirmar uma realidade já descrita por Chagas, tanto do ponto de vista clínico quanto social. A afirmação da filiação e da continuidade em relação aos enunciados de $C$ arlos $C$ hagas encontra-se presente, com grande ênfase, na narrativa dos próprios cientistas do C E PM C, e deve ser vista como estratégia fundamental utilizada por estes atores no processo de construção da doença aqui examinado. N o entanto, adoto uma perspectiva de análise que rejeita a concepção de que as idéias científicas se desenvolvem natural mente em direção à verdade, na medida em se aperfeiçoam os métodos para desvelá-la. N um processo que não teve nada de natural nem de inexorável, argumento que a renovação do interesse pela

\footnotetext{
${ }^{37}$ E m 1953, o M inistério da E ducação e Saúde desdobrou-se em duas pastas e, três anos depois, como a principal medida do governo J K para a área da saúde, foi criado, no M inistério da Saúde, o D epartamento $\mathrm{N}$ acional de Endemias Rurais.

${ }^{38}$ E m 1991, uma reunião em Brasília selou um acordo entre os países do Cone Sul para a erradicação da principal espécie vetora nesta região, o Triatoma infestans.
} 
doença e os acordos produzidos sobre sua identidade médica e social foram o resultado de um processo coletivo e negociado, possível graças a condições e contextos históricos e sociais específicos, relacionados ao lugar e aos sentidos que se pretendeu atribuir àquele tema num determinado projeto institucional, por sua vez referido ao contexto mundial e da sociedade brasileira da época.

Se D ias e seus colaboradores foram bem sucedidos em superar certas dúvidas sobre a doença, atrair para o tema outros grupos, cientistas e não cientistas, e garantir condições básicas para sua legitimação científica e social, isto se deu não porque produziram evidências inquestionáveis a partir das quais tais grupos foram convencidos, mas justamente porque foram capazes de convencê-los a aceitarem seus enunciad os como evidências de uma dada realidade. Como sugere T homas K uhn, a luneta de G alileu não forneceu provas da correção do esquema conceitual de Copérnico, mas constituiu, naquele mundo renascentista, um poderoso instrumento de propaganda e persuasão em torno do novo cosmos construído por tal esquema ${ }^{39}$. N o caso da doença de Chagas, foi num ambiente histórico-social marcado pela ânsia em remover os obstáculos ao desenvolvimento, entre os quais as doenças transmissíveis, que os cientistas buscaram as estratégias e os sentidos, políticos e simbólicos, que os tornaram capazes de convencer que aquela entidade médica, expressa nos dados produzidos pelo eletrocardiógrafo e por outros procedimentos técnicos, fazia sentido para os interesses presentes na sociedade brasileira, naquele momento.

\footnotetext{
${ }^{39}$ T homas K uhn, L a révolution copernicienne, Paris, F ayard, 1973, p. 302.
} 